\title{
Biological activity of binary mixtures of 2,4-D with some aminophosphonates
}

\author{
Janusz Sarapuk, Dorota Bonarska, Halina Kleszczy ńska \\ Department of Physics and Biophysics, Agricultural University, Wrocław, Poland
}

\begin{abstract}
Summary
A series of cyclic and acyclic aminophosphonates was synthesized for agrochemical application. The compounds differed in the substituents at the carbon, nitrogen and phosphorus atoms. Their potential biological activity was checked by studying their hemolytic potency, since hemolysis of erythrocytes by various compounds was found earlier to be a good indicator of their pesticidal efficiency. A series of hemolytic experiments permitted us to check the pesticidal efficiency of aminophosphonates and to determine what structural features of aminophosphonates are responsible for it.

Parallelly, we studied the hemolytic efficiency of binary mixtures of the aminophosphonates with the well-known herbicide 2,4-dichlorophenoxyacetic acid (2,4-D... The aim was to check if potential biological efficiencies could be enhanced in comparison with those found for individual components due to interactions between aminophosphonates and 2,4-D. An analysis of the effects binary mixtures was carried out by constructing graphs for both components of binary mixtures that give the same hemolysis (the isobole method).
\end{abstract}

Keywords: aminophosphonates - biological activity - erythrocytes - binary mixtures

\section{INTRODUCTION}

Aminophosphonates belong to a group of compounds some of which are well-known and widely used because of their biological activity. They were found to influence biochemical processes in plant cells, modifying or inhibiting them (Forlani et al. 1997, Öruç and Üner 1999, Agrawal et al. 1995). This is the reason why new compounds of this group are synthesized and checked for potential bioactivity. This is a rather long and tedious procedure and to accelerate it and eliminate compounds of little biological usefulness, different approaches to the problem can be applied. One of these is to use biological or model lipid membranes like erythrocytes, liposomes or planar lipid membranes, especially when the compounds, because of their structural lipophilicity, easily interact with the membranes and thus affect their toxicity (Suwalsky et al. 1996, 1999, 2000). The aminophosphonates studied in this work belong to such lipophilic compounds and this was the reason why hemolysis of erythrocytes was chosen as a preliminary technique to check their potential biological activity. It must be noted that hemolytic experiments with a large spectrum of different compounds, aminophosphonates including, have shown that, indeed, hemolysis of erythrocytes is a good measure of biological activity of these compounds (Ponder 1948, Kleszczyńska et al. 2001, Trela et al. 2001).

Mixtures of two or more bioactive compounds are nowadays used for various reasons, the most important being to widen the spectrum of biological activity and, in some cases, to reduce the concentrations of mixture components without loss of activity (Gisi 1996). This may occur when, due to the possible interaction between compounds used in mixtures, their individual activity may be enhanced the so-called synergistic type interaction (Tripathi and Agarwal 1997). It is also possible that biological activity may be diminished - the antagonistic type interaction (Mora and Earle 2001) - or no interaction between the mixture components 
is observed - the additive type of interaction (Kortenkamp and Altenburger 1998). In the present case we wanted to check if there were any interactions between 2,4-dichlorophenoxyacetic acid (2,4-D) and aminophosphonates that increased the overall activity while the concentrations of the components could be reduced, i. e., if the most desired synergistic interactions occurred.

Phenoxyacetic herbicide 2,4-D was chosen as a second binary mixtures component, since it is one of the most common and widely used biologically active compounds (Suwalsky et al. 1996, Öruç and Üner 1999, 2000) and may cause toxic effects by inducing changes in cell membrane organization (Duchnowicz et al. 2002, Duchnowicz and Koter 2003, Suwalsky et al. 1999). Recently, we have studied its binary mixtures with a few other phenoxy and organophosphorous compounds, however, non of those produced a synergistic effect (Kleszczyńska et al. 2003).

\section{MATERIAL AND METHODS}

All the pesticides studied were synthesized in the Department of Organic Chemistry, Biochemistry and Biotechnology of the Technical University of Wrocław. The purity was checked by ${ }^{1} \mathrm{H}-\mathrm{NMR}$ and ${ }^{31} \mathrm{P}-\mathrm{NMR}$ spectra. Their general structure is shown in Table 1.

Pig erythrocytes were used in the hemolytic experiments. Erythrocytes (RBC) were washed four times in isotonic phosphate buffer $(\mathrm{pH}$ 7.4) and incubated in the same buffer with the addition of chosen concentrations of aminophosphonates or equimolar mixture of two pesticides for 1 hour at $37^{\circ} \mathrm{C}$. After the modification, samples were taken at $10 \mathrm{~min}$ intervals, centrifuged and hemoglobin content in supernatant measured with Specol 11 spectrophotometer at $540 \mathrm{~nm}$. Hematocrite was $2 \%$. The hemolytic curves obtained permitted us to determine the concentrations of the compounds causing $50 \%$ hemolysis $\left(\mathrm{C}_{50}\right)$.

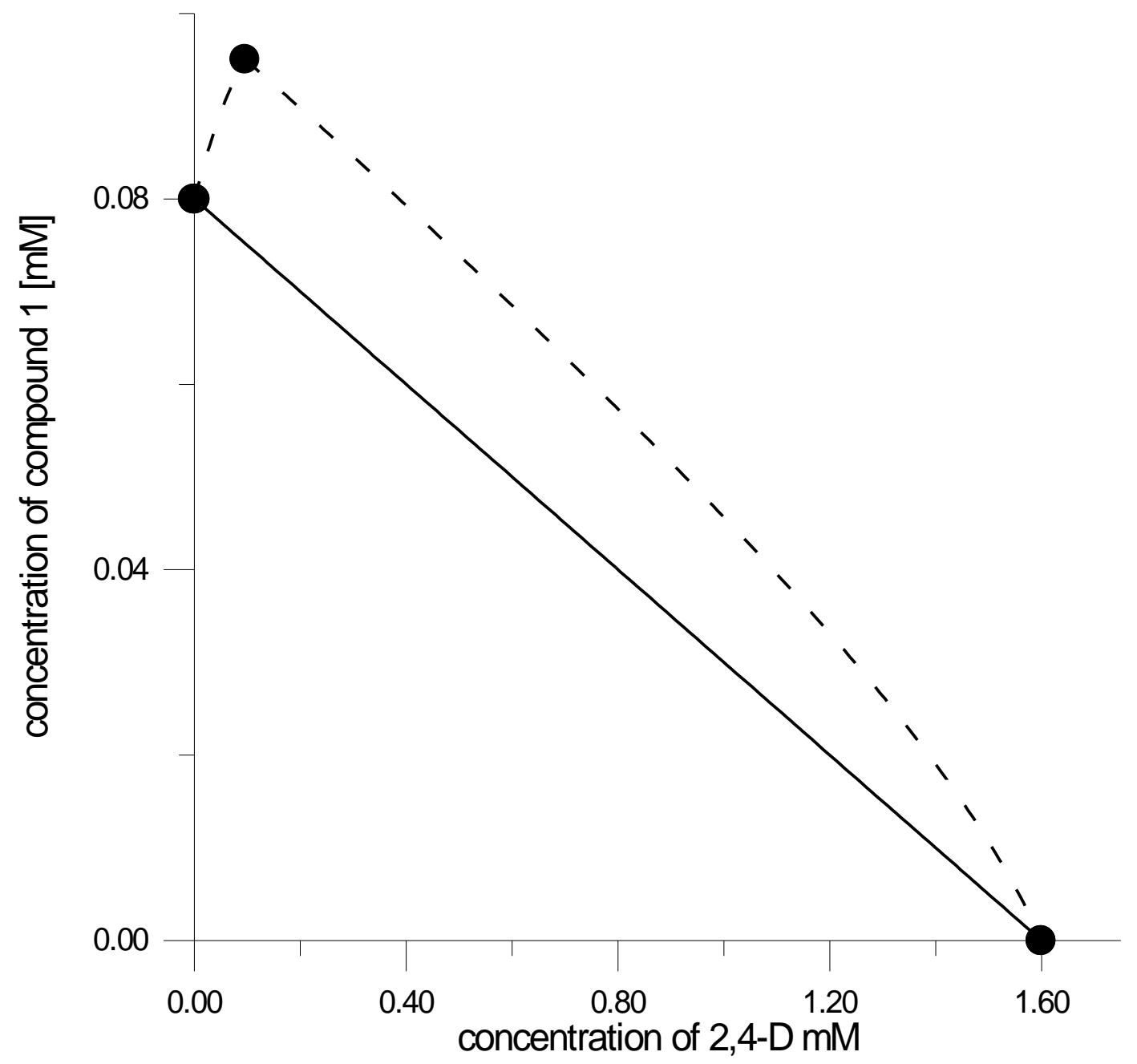

Fig. 1. Isobole obtained for equimolar binary mixture of compound 1 with dichlorophenoxyacetic acid (2,4-D) 
Table 1. The structure and substituent groups of the aminophosphonate

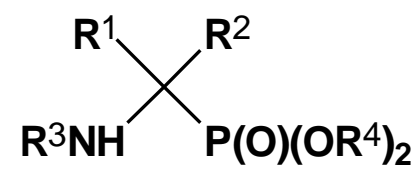

\begin{tabular}{ccccc}
\hline & \multicolumn{2}{c}{$\mathrm{R}^{1}$} & $\mathrm{R}^{2}$ & $\mathrm{R}^{3}$ \\
\hline 1 & $\mathrm{CH}_{3}$ & $\mathrm{CH}_{3}$ & $\mathrm{n}-\mathrm{C}_{8} \mathrm{H}_{17}$ & $\mathrm{n}-\mathrm{C}_{4} \mathrm{H}_{9}$ \\
2 & $-\mathrm{C}_{4} \mathrm{H}_{8}-$ & & $\mathrm{n}-\mathrm{C}_{4} \mathrm{H}_{9}$ & $\mathrm{n}-\mathrm{C}_{4} \mathrm{H}_{9}$ \\
3 & $-\mathrm{C}_{2} \mathrm{H}_{4} \mathrm{C}\left(\mathrm{t}-\mathrm{C}_{4} \mathrm{H}_{9}\right) \mathrm{C}_{2} \mathrm{H}_{4-}$ & $\mathrm{n}-\mathrm{C}_{4} \mathrm{H}_{9}$ & $\mathrm{n}-\mathrm{C}_{4} \mathrm{H}_{9}$ \\
4 & $-\mathrm{C}_{5} \mathrm{H}_{10-}$ & $\mathrm{n}-\mathrm{C}_{8} \mathrm{H}_{17}$ & $\mathrm{n}-\mathrm{C}_{4} \mathrm{H}_{9}$ \\
5 & $-\mathrm{C}_{5} \mathrm{H}_{10-}$ & $\mathrm{n}-\mathrm{C}_{14} \mathrm{H}_{29}$ & $\mathrm{n}-\mathrm{C}_{4} \mathrm{H}_{9}$ \\
\hline
\end{tabular}

To evaluate the binary mixture effects, the isobole method was used (Kortenkamp and Altenburger 1998). The values of $C_{50}$ obtained for particular components were marked on $\mathrm{X}$ and $\mathrm{Y}$ axis and connected wth straight lines. The points on the line predicted the combinations of both components that yield the same effect (50\% hemolysis). If binary mixtures gave a point that belonged to this line, the interaction between the components was defined as additive. In such cases the components can be viewed as behaving like dilutions of each other. Experimental points above or below the isobole may be defined as antagonistic and synergistic interaction, respectively.

Table 2. The concentrations of compounds studied and their binary mixtures with dichlorophenoxyacetic acid (2,4D) inducing $50 \%$ hemolysis of erythrocytes $\left(\mathrm{C}_{50}\right)$.

Compound $\quad \mathrm{C}_{50}$ for individual compound $[\mathrm{mM}] \quad \mathrm{C}_{50}$ for binary mixtures of compounds with 2,4-D [mM]

\begin{tabular}{lll}
\hline 1 & 0.081 & 0.095 \\
2 & 0.86 & 0.35 \\
3 & 0.77 & 0.40 \\
4 & 0.42 & 0.10 \\
5 & 0.83 & 0.30 \\
\hline
\end{tabular}

\section{RESULTS AND DISCUSSION}

The results of the hemolytic experiments are collected in Table 2, which contains the values of concentrations of particular compounds and their binary mixtures with 2,4-D that cause 50\% hemolysis of erythrocyte membranes $\left(\mathrm{C}_{50}\right)$. The table shows that the ability of the compounds to influence RBC membranes differed. The best was found for acyclic compound. Hemolytic efficiencies of cyclic 
compounds were worse but, generally, all aminophosphonates were found to exhibit a good hemolytic potency and are thus expected to have good potential biological activity. These results confirm obtained earlier and show that aminophosphates studied may be included into membrane-active compounds (Trela et al. 2001, Grzyś et al. 2001). Hemolytic curves obtained for binary mixtures of aminophosphonates with 2,4-D enabled us to determine their hemolytic efficiencies and the kind of interaction between mixture compounds. As in experiments with individual compounds, the hemolytic efficiencies of binary mixtures were quite good. However, the binary mixture of acyclic aminophosphonate with 2,4-D hemolyzed erythrocytes was significantly weaker than the compound alone. It suggested that those compounds compete for the same binding sites or a different kind of interaction with 2,4-D, than that for cyclic compounds may occur.

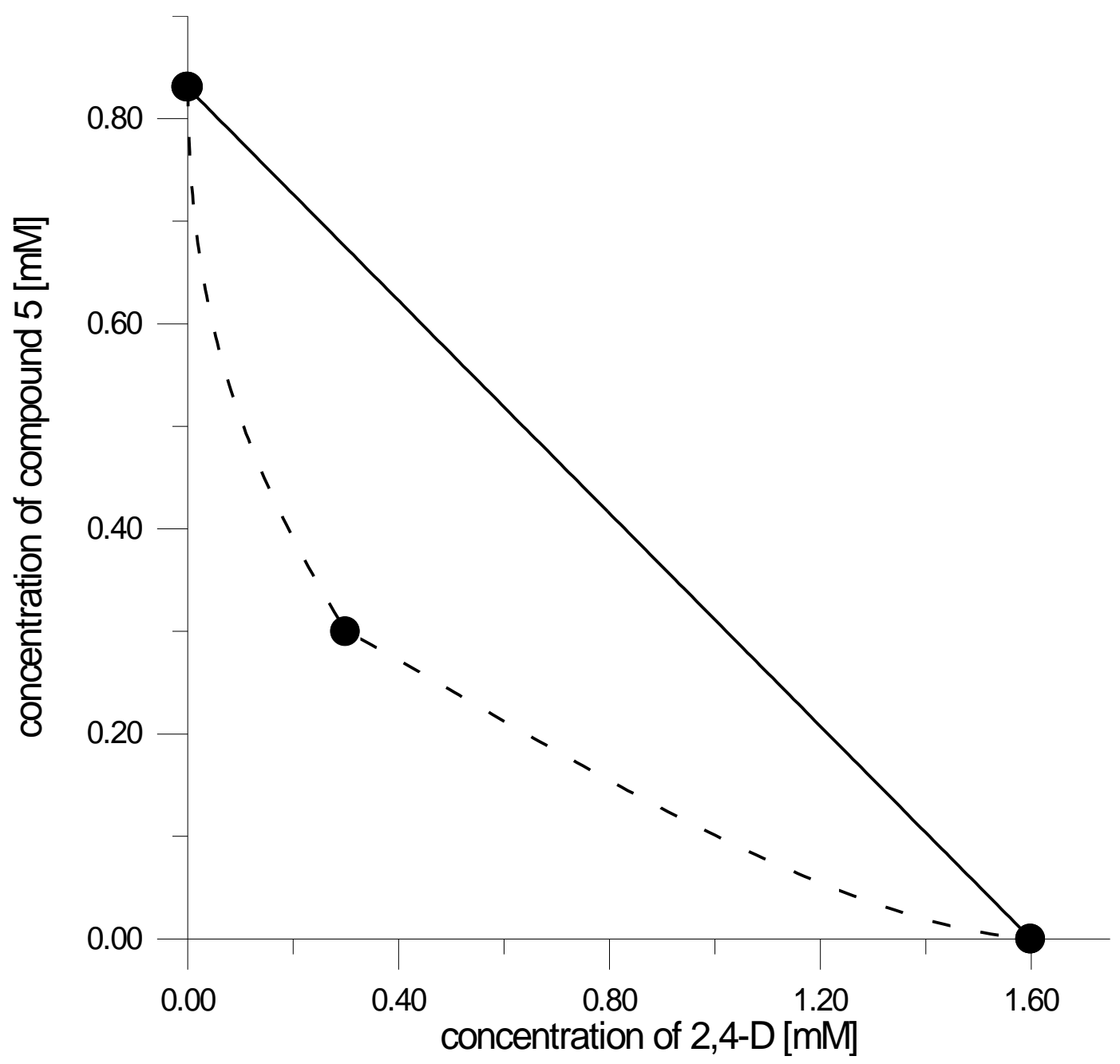

Fig. 2. Isobole obtained for equimolar binary mixture of compound 5 with dichlorophenoxyacetic acid (24-D)

There are different approaches to determine those interactions (Gisi 1996, Pape-Lindstrom and Lydy 1997, Kortenkamp and Altenburger 1998). We have used the isobole method for that purpose. The results are shown in Figs. 1 and 2. All cyclic compounds were found to interact synergistically with 2,4-D herbicide. Fig. 1 presents isobole for the interaction between compound B and 2,4-D. Similar results were obtained for binary mixtures of this herbicide with other cyclic aminophosphonates. The isobole constructed for a 2,4-D-acyclic aminophosphonate shows that there is antagonism between the compounds (Fig. 2). These results seem to classify the cyclic aminophosphonates studied for agrochemical application both individually and in the mentioned mixtures. The same is valid for the acyclic compound when used individually. Its antagonistic interaction with 2,4-D excludes the possibility of using the compound in binary mixtures with 2,4-D. 


\section{ACKNOWLEDGEMENTS}

This work was sponsored by the Polish Research Committee (KBN), grant no. 6 P04G 09621.

Received 30 ${ }^{\text {th }}$ May 2003.

Published online $11^{\text {th }}$ July 2003.

\section{REFERENCES}

Agrawal D., A. Subramoniam, F. Afaq: Influence of hexachlorocyclohexane on phosphoinositides in rat erythrocyte membranes and brain. Toxicol. 95: 135-140, 1995.

Duchnowicz P. and M. Koter: Damage to the erythrocyte membrane caused by chlorophenoxyacetic herbicides. Cell. Mol. Biol. Lett. 8: 25-30, 2003.

Duchnowicz P., M. Koter, W. Duda: Damage of erythrocyte by phenoxyacetic herbicides and their metabolites. Pest. Biochem. Physiol. 74: 17, 2002.

Forlani G., B. Lejczak, P. Kafarski, P. Wieczorek: Mode of action of herbicidal derivatives of aminomethylenebiophosphonic acid. Part II. Reversal of herbicidal action by aromtic amino acids. J. Plant. Growth Regul. 16: 147-152, 1997.

Gisi U.: Synergistic action of fungicides in mixtures. Phytopathol. 86: 1273-1279, 1996.

Grzyś E., K. Bielecki, J. Sarapuk: Aminophosphonate-induced changes of betacyanine and ionic efflux. Z. Naturforsch. 56c: 349-352, 2001.

Kleszczyńska H., J. Sarapuk, D. Bonarska: The hemolytic toxicity of some new aminophosphonates. Cell. Mol. Biol. Lett. 6: 271-275, 2001.

Kleszczyńska H., D. Bonarska, K. Bielecki, J. Sarapuk: The hemolytic and physiological activities of mixtures of some phenoxy and organophosphorous herbicides. Cell. Mol. Biol. Lett. 8: 55-61, 2003.
Kortenkamp A. and R. Altenburger: Synergisms with mixtures of xenoestrogens: A reevaluation using the method of isoboles. Sci. Total Environ. 221: 59-73, 1998

Mora A. and E. D. Earle: Combination of Trichoderma harzianum endochitinase and membrane-affecting fungicide on control of Alternaria leaf spot in transgenic brocolli plants. Appl. Microbiol. Biotechnol. 55: 306-310, 2001.

Öruç E. O. and N. Üner: Effects of 2,4-Diamin on some parameters of protein and carbohydrate metabolisms in the serum, muscle and liver of Cyprinus carpio. Environ. Pollution, Part C: 267-272, 1999.

Öruç E. O. and N. Üner: Combined effects of 2,4-D and azinphosphometyl on antioxidant enzymes and lipid peroxidation in liver of Oreochromis niloticus. Comp. Biochem. Physiol. Part C, 127: 291-296, 2000.

Pape-Lindstrom P. A. and M. J. Lydy: Synergistic toxicity of atrazine and organophosphate insecticides contravenes the response addition mixture model. Environ. Toxicol. Chem. 16: 2415-2420, 1997.

Ponder E.: Hemolysis and related phenomena. J. A. Churchill Ltd, London, 1948.

Suwalsky M., M. Benites, B. Norris, P. Sotomayor: Toxic effects of the fungicide benomyl on cell membranes. Comp. Biochem. Physiol. Part C, 125: 111-119, 2000.

Suwalsky M., M. Benites, F. Villena, F. Aguilar, P. Sotomayor: Interaction of 2,4dichlorophenoxyacetic acid (2,4-D) with cell and model membranes. Biochim. Biophys. Acta 125: 111-119, 1996.

Suwalsky M., L. Quevedo, B. Norris, M. Benites: Toxic action of the herbicide 2,4-D on the neuroepithelial synapse and on the nonstimulated skin of the frog Caudiverbera caudiverbera. Bull. Environ. Contam. Toxicol. 62: 570-577, 1999.

Trela Z., H. Kleszczyńska, J. Sarapuk: Physiological and hemolytic toxicity of some aminophosphonates. Z. Naturforsch. 56c: 838842, 2001.

Tripathi A. M. and R. A. Agarwal: Synergism in tertiary mixture of pesticides. Chemosphere 35: 2365-2374, 1997.

\section{* Address:}

Janusz Sarapuk, Department of Physics and Biophysics, Agricultural University, Norwida 25, 50-375 Wrocław, Poland; Js@ozi.ar.wroc.pl 